

\title{
Desenvolvimento de sistema de apoio com depósito cerâmico para soldagem e processamento por atrito com pino não consumível
}

\section{(Development of ceramic backing for friction stir welding and processing)}

\author{
Tiago F. A. Santos, ${ }^{1,2,3}$, Edwar A. Torres ${ }^{1,2,4}$, Tahiana F.C. Hermengildo ${ }^{1,2}$, Antonio J. Ramirez ${ }^{1,2, *}$ \\ ${ }^{1}$ Laboratório Nacional de Nanotecnologia - LNNano, Campinas, São Paulo, Brasil \\ ${ }^{2}$ Faculdade de Engenharia Mecânica (FEM), Uncamp, Campinas, São Paulo, Brasil \\ ${ }^{3}$ Atualmente no CPqD, Campinas, São Paulo, Brasil \\ ${ }^{4}$ Instituto Tecnológico Metropolitano - ITM, Medellín, Antioquia, Colômbia
}

\begin{abstract}
Resumo
A mesa suporte das peças a serem unidas normalmente se deforma durante o processo de soldagem por atrito com pino não consumivel devido às altas cargas envolvidas. Consequentemente, a obtenção de juntas soldadas com penetração total, bem como a vida útil da amostra e da ferramenta podem ser afetadas, causando paradas não programadas e comprometendo a produtividade do processo e deslocando mão de obra para uma etapa de manutenção não prevista na cadeia do processo de soldagem. Este trabalho apresenta uma mesa de apoio com depósito cerâmico para o processamento e soldagem por atrito com pino não consumível. Para o desenvolvimento da mesa foram testados quatro depósitos cerâmicos, sob uma placa de aço, dos quais o de menor porosidade atingiu melhor desempenho. Essa mesa permitiu a realização de juntas soldadas com penetração completa de aços inoxidáveis duplex; resistir às altas cargas durante a soldagem de aços baixa liga alta resistência e realizar juntas dissimilares aço-aluminio, sem aderência do material mais macio à mesa suporte; bem como outras importantes características como confinar o calor e o metal plastificado, assim como determinar parâmetros de soldagem estáveis.
\end{abstract}

Palavras-chave: Soldagem e processamento por atrito com pino não consumível; mesa de apoio; penetração total.

\section{Abstract:}

Usually, the workpiece is deformed during the friction stir welding, due to high applied loads. Consequently, fully and consolidated friction stir welded joints as well as tools life time can be affected promoting unscheduled manufacturing stops which favorites decreasing the welding productivity. Furthermore, the workforce is dislocated to not predicted maintenance steps. This work proposes the development of a special ceramic backing to joining and processing material using FSW technologies. Four ceramic deposits were tested over a steel plate, which allowed selecting those with less porosity and, thus, better strength. This backing allowed to obtain full penetration welds for duplex stainless steels, to resist high forces during engage for high strength low alloy steels and to obtain consolidated aluminum-steel dissimilar joints. For the last one, there was not adherence of the soft material in workpiece. In addition, the ceramic backing allowed confine the heat and plasticized metal, as well as developing established welding parameters.

Key-words: Friction stir welding and processing; backing; full penetration.

\section{Introdução}

A tecnologia de soldagem ou processamento por atrito com pino não-consumível (SAPNC e PAPNC), mais conhecidas como FSW e FSP, do inglês friction stir welding (FSW) e friction stir processing (FSP), respectivamente, é uma tecnologia

Recebido em 17/02/2014, texto final em 11/04/2014

DOI: 10.1590/0104-9224/SI1902.02 de união e processamento de materiais no estado sólido, que foi desenvolvido e patenteado em 1991 pelo TWI (The Welding Institute) em Cambridge, Reino Unido [1]. Este processo de soldagem, derivado da soldagem convencional por atrito, utiliza uma ferramenta não consumível para produzir calor concomitantemente a uma deformação plástica severa ao longo da junta. A ferramenta é constituída de um ombro e um pino; o primeiro é responsável pela geração de calor durante o contato com a junta, enquanto o segundo agita o metal plastificado. Neste processo a ferramenta gira a velocidade de rotação determinada, penetran-

* Autor para quem toda a correspondência deve ser encaminhada (antonio.ramirez@lnnano.cnpem.br) 
do na junta e aquecendo o metal em contato com a ferramenta. Uma vez atingida a penetração do ombro, o atrito com a junta gera calor e o amolecimento do metal circundante, que é constantemente misturado pelo pino. Após isso, ocorre o avanço da ferramenta ao longo da junta, realizando-se a união dos metais [2]. Um esquema do processo é apresentado na Figura 1.

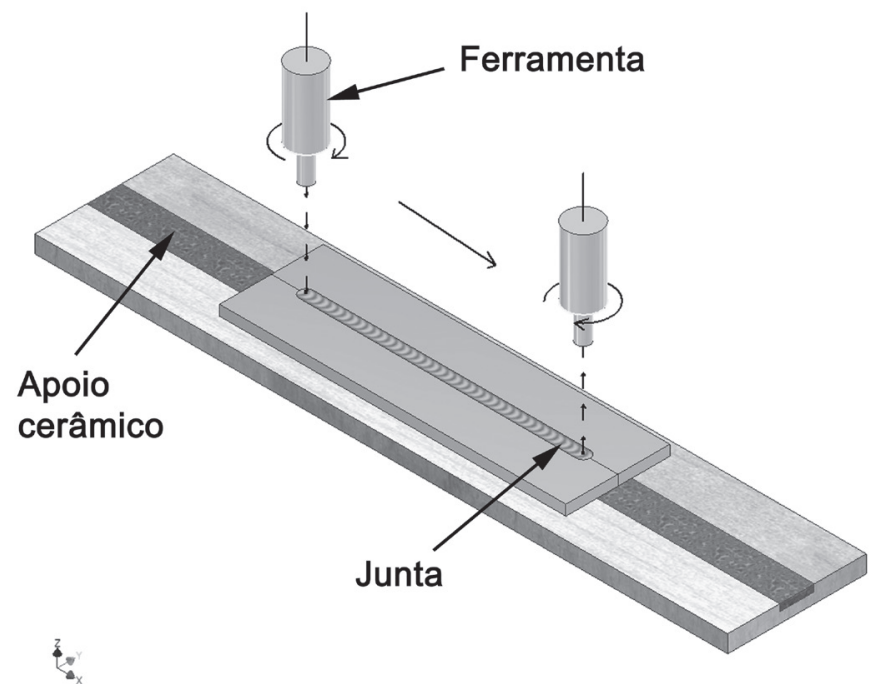

Figura 1. Desenho esquemático da soldagem a topo por atrito com pino não consumível sobre mesa de apoio com depósito cerâmico.

Muitos autores têm estudado o processo de SAPNC para diversos sistemas ferrosos e não ferrosos [3]. No entanto, são poucas as referências relatando o efeito da mesa de apoio na obtenção de juntas consolidadas, sendo a maior parte relacionada com o efeito desta na transferência de calor durante o processo $[4,5]$. Um dos poucos trabalhos referentes ao backing foi o desenvolvido por Rosales et al. [6] que determinaram o efeito do material do apoio na transferência do calor gerado na zona de mistura durante a soldagem de ligas de alumínio. Apesar de determinarem uma relação entre o apoio e o calor na junta, os resultados avaliaram os efeitos relativos à condutividade térmica do backing, mas o trabalho não discutiu o efeito do apoio na obtenção de juntas sem defeito. A relação entre o apoio, o calor gerado e a formação de defeitos foi realizada por Upadhyay \& Reynolds [7], que determinaram o efeito da força axial e da chapa de apoio na geração e condução de calor em juntas soldadas de alumínio; nesta contribuição os pesquisadores conseguiram, para os mesmos parâmetros de soldagem, obter juntas sem defeitos e mudanças microestruturais significativas. Como resultado da força de forjamento e a concentração de calor induzidos pela placa de apoio; o aumento na temperatura permitiu alcançar maior fluidez do metal de soldagem, com preenchimento mais eficaz da junta, evitando a formação de vazios. No entanto, com os resultados apresentados no trabalho, não foi possível evidenciar se as juntas conseguiram a penetração total e avaliar a quantidade de rebarba gerada. Da mesma forma, como o metal de base para as juntas é a liga de alumínio 6056, os resultados são limitados a metais de baixo ponto de fusão, já que embora a penetração completa tenha sido atingida na soldagem de materiais de baixa temperatura de fusão, o alcance para materiais de alta temperatura de fusão ou juntas dissimilares continua a ser um desafio, visto que cargas e temperaturas elevadas estão envolvidas neste processo $[8,9]$.

Nessas condições a formação de defeitos como falta de penetração, vazios, excesso de rebarba e aderência da junta soldada à mesa de apoio, são comuns $[10,11]$. Um dos defeitos mais recorrentes é a falta de penetração, que pode ser corrigida com o aumento da penetração ou da carga axial sob a ferramenta. Entretanto, existem três limitações técnicas que dificultam esta operação: a) o aumento da carga pode deformar a mesa de apoio sendo necessária a fabricação de uma nova mesa; b) o material da junta plastificado pelo atrito é empurrado para abaixo pela ferramenta, mas a deformação do apoio impede a consolidação da junta; c) o material soldado pode aderir à mesa visto que alta carga em temperaturas elevadas favorece a soldagem do material à mesa. Por outro lado, o excesso de penetração da ferramenta pode trazer consequências como o aumento do aporte energético na junta soldada, que pode ocasionar superaquecimento e consequentes alterações microestruturais na junta soldada, além de afetar ou diminuir a vida útil da ferramenta de SAPNC, devido às condições mais severas de carga e temperatura.

Uma solução envolve o uso de um apoio com um material suficientemente duro, que evite a deformação da mesa. Porém, este material deve suportar tanto as cargas como as temperaturas elevadas, não ser reativo com os materiais a serem unidos para evitar sua aderência, e ter uma durabilidade e custo que permitam sua implementação em nível industrial. Alguns depósitos cerâmicos podem ser considerados como apropriados por cumprir as condições mencionadas. Embora já exista uma patente que descreve o uso destes materiais como apoio [12], esta descreve de forma geral o uso de depósito cerâmico, mas não apresenta uma análise dos depósitos cerâmicos. Portanto, o depósito de material cerâmico ou liga refratária constitui uma vantagem por ser mais rígido e ser facilmente aplicado por meio do processo de aspersão térmica. Já que a mesa de apoio cerâmica não sofre deformação quando submetida à cargas elevadas, o metal plastificado permanece contido, permitindo um fluxo homogêneo durante a agitação, alcançando a penetração completa, além de possibilitar a concentração do calor na região da junta [13]. Esta condição é especialmente importante para juntas dissimilares onde um dos materiais possui alta condutividade térmica, como é o caso do cobre. Outra importante característica é a possibilidade de avaliação da adesão de alumínio durante a soldagem dissimilar aço-alumínio, problema este que limita a aplicação do processo SAPNC para sistemas aço-alumínio e, consequentemente, limita a aplicação do processo na indústria automobilística. Este trabalho descreve o efeito do uso da placa de apoio com depósito cerâmico na confecção de juntas soldadas livres de defeitos em junta a topo de metais de alta resistência e uniões dissimilares.

\section{Materiais e Métodos}

A chapa de apoio com depósito cerâmico para SAPNC e PAPNC consiste em um depósito cerâmico realizado sobre um substrato de aço 1045 de $800 \mathrm{~mm}$ x $60 \mathrm{~mm}$ x $10 \mathrm{~mm}$ que compõe a parte central da mesa suporte da máquina para soldagem 
ou processamento por atrito com pino. As dimensões do volume de depósito podem ser diferentes em função da região soldada ou processada. Nesta peça foi realizada usinagem para gerar um rasgo em cada face com dimensões aproximadas de $620 \mathrm{~mm}$ de comprimento, $25 \mathrm{~mm}$ de largura e $1,2 \mathrm{~mm}$ de profundidade conforme desenho esquemático da Figura 2.

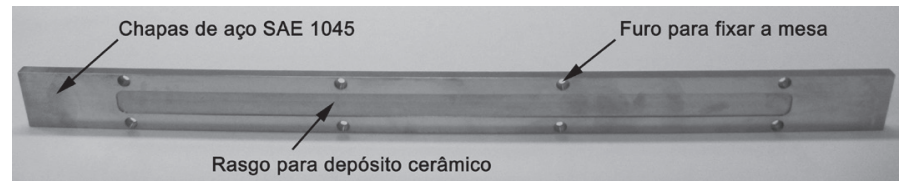

Figura 2. Mesa de apoio da máquina de soldagem e processamento por atrito com pino não consumível após usinagem para receber o depósito cerâmico.

Como revestimento cerâmico foram utilizados óxido de cromo $\left(\mathrm{Cr}_{2} \mathrm{O}_{3}\right)$, dióxido de titânio $\left(\mathrm{TiO}_{2}\right)$, alumina $\left(\mathrm{Al}_{2} \mathrm{O}_{3}\right)$ e $\mathrm{Al}_{2} \mathrm{O}_{3}$ $-\mathrm{TiO}_{2}$, que foram aplicados por meio de aspersão por chama oxiacetilênica na forma de pó e de cordão com diâmetro $1 / 8$ pol. A técnica de aspersão térmica foi selecionada, pois garante a elevada aderência, baixa porosidade, facilidade de deposição e custo adequado, comparado com outras técnicas de proteção de materiais. O revestimento foi aplicado diretamente sob o substrato, com preparação prévia utilizando-se jateamento com óxido de alumínio marrom de pureza $95 \%$ e preaquecido a $80{ }^{\circ} \mathrm{C}$. Após depósito, foi realizada a retífica da peça metálica com o depósito para adequá-la novamente à mesa suporte. Alguns cuidados foram tomados na escolha do depósito cerâmico, o material não poderia ter coeficiente de dilatação térmica muito grande devido aos ciclos térmicos que o mesmo experimentaria durante o processo de SAPNC e deveria ter uma usinabilidade adequada para o processo de retífica pós-depósito. É conhecido que a existência de poros é intrínseca do processo de aspersão térmica. Esses poros podem constituir núcleos para o início de trincas quando a peça for submetida à solicitação. Nas chapas revestidas, foi observado que, após o processo de retífica, a porosidade tornou-se evidente. No total, foram fabricadas quatro chapas cada uma com deposito cerâmico em cada face.
As chapas foram colocadas na mesa da máquina para SAPNC e realizadas juntas soldadas a topo empregando como metais de base o aço de baixa liga alta resistência X80; os aços inoxidáveis duplex UNS S32101 e UNS S32205 e os superduplex UNS S32750 e S32760; e juntas dissimilares aço-alumínio empregando a liga AA6063-T5 e o aço AISI SAE 1020. As ferramentas empregadas para a soldagem dos aços de alta resistência e inoxidáveis foram de nitreto de boro cúbico policristalino (Polycrystalline Cubic Boron Nitride, PCBN) e o compósito de $60 \%$ vol. de PCBN em matriz metálica de $40 \%$ vol. WRe (30\% vol. Re), enquanto para as juntas dissimilares foi de carbeto de tungstênio (WC-12Co). As espessuras das chapas, as caraterísticas das ferramentas e os parâmetros de soldagem são apresentados na Tabela 1. Para a realização das juntas dissimilares foi empregado um parâmetro adicional denominado deslocamento da ferramenta (offset), o qual corresponde a distância da tangente do pino à linha da junta, e que para este caso foi de 0,5 e 1,5 $\mathrm{mm}$. Em todos os casos, a penetração da ferramenta foi realizada utilizando controle de força, sendo os valores apresentados na Tabela 1. Entretanto, para as juntas alumínio-aço o mecanismo mais eficaz para estabilizar a penetração da ferramenta foi utilizando controle por posição, sendo a penetração de 1,65 mm.

As juntas soldadas foram executadas mediante o uso de equipamento de SAPNC, que permite o controle de posição e de força axial durante a soldagem, modelo RM-1a da Transformation Tecnhnologies Inc. com capacidade de força axial de $67 \mathrm{kN}$, velocidade de avanço de $3000 \mathrm{~mm}$. $\mathrm{min}^{-1}$ e velocidade de rotação de $3000 \mathrm{rpm}$. Este equipamento possui um sistema de telemetria que permite o monitoramento da temperatura da ferramenta em tempo real. Embora o termopar da ferramenta não registre a temperatura no centro da junta soldada, é possível ter valores comparativos para diferentes parâmetros de soldagem devido à alta condutividade térmica da ferramenta de PCBN [14].

As juntas soldadas foram avaliadas por meio de inspeção visual, líquidos penetrantes e testes de dobramento de raiz, na procura de faltas de penetração, e ensaios de tração. Paralelamente, foram realizados cortes transversais à linha da junta e realizado macro ataque para verificar a ausência de vazios e a penetração total da junta.

Tabela 1. Metais de base, caraterísticas das ferramentas e parâmetros de soldagem.

\begin{tabular}{|c|c|c|c|c|c|c|c|}
\hline \multirow{2}{*}{ Metal de base } & \multirow{2}{*}{ Espessura $[\mathrm{mm}]$} & \multicolumn{3}{|c|}{ Caraterísticas ferramenta [mm] } & \multicolumn{3}{|c|}{ Parâmetros de soldagem } \\
\hline & & $\varnothing_{\mathrm{H}}$ & $\varnothing_{\mathrm{P}}$ & $\mathrm{CP}_{\mathrm{P}}$ & $\omega[\mathrm{rpm}]$ & $v\left[\mathrm{~mm} \cdot \min ^{-1}\right]$ & $\mathrm{F}[\mathrm{kN}]$ \\
\hline ISO 3183 X80M & 10,0 & \multirow{5}{*}{36,8} & \multirow{5}{*}{10} & \multirow{5}{*}{5,74} & $350 / 500$ & 100 & 33 \\
\hline UNS S32101 & \multirow{4}{*}{6,0} & & & & \multirow{4}{*}{200} & \multirow{4}{*}{100} & \multirow{4}{*}{37} \\
\hline UNS S32205 & & & & & & & \\
\hline UNS S32750 & & & & & & & \\
\hline UNS S32760 & & & & & & & \\
\hline AA6063 -SAE1020 & 2,0 & 25,0 & 5,7 & 1,35 & 300 & 150 & $6,8-7,3$ \\
\hline$\varnothing_{\mathrm{H}}$ Diâmetro do omb & & & & cidade & tação & & \\
\hline$\emptyset_{\mathrm{P}}$ Diâmetro do pino & & & & cidade & janço & & \\
\hline $\mathrm{C}_{\mathrm{P}}$ Comprimento do & & & & axial & & & \\
\hline
\end{tabular}



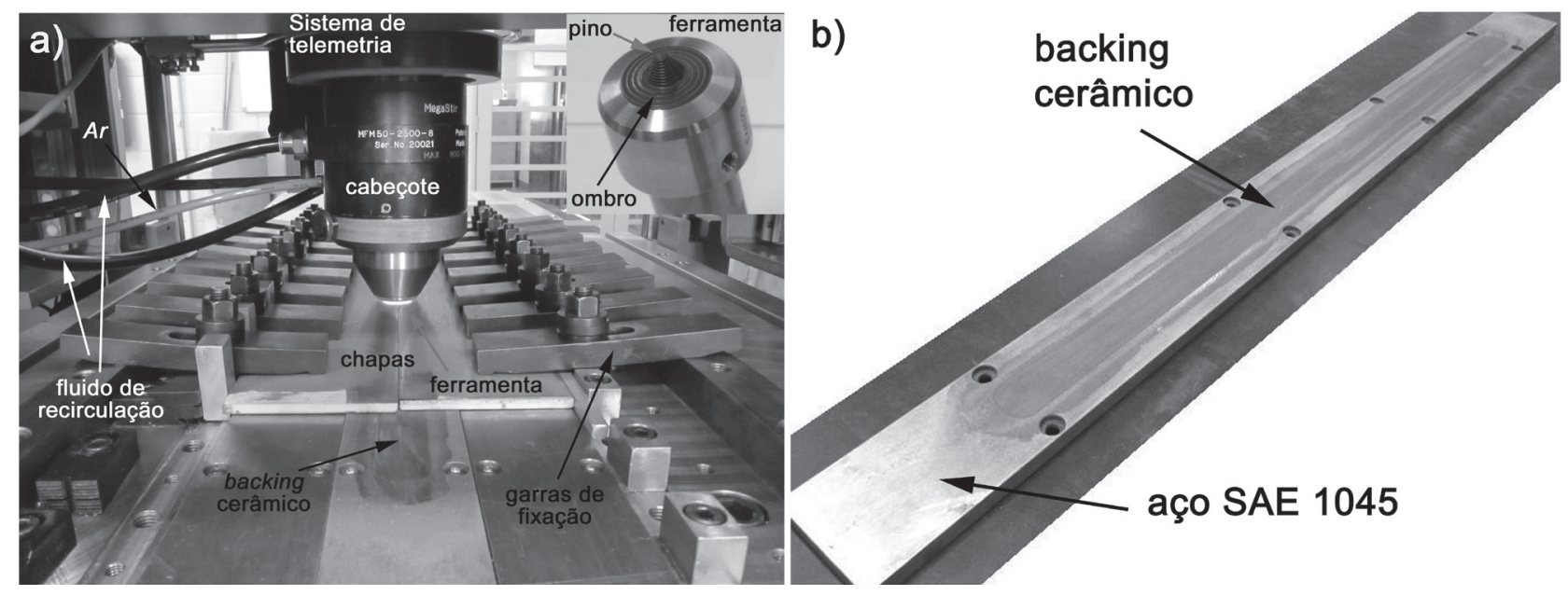

Figura 3. a) Montagem experimental do equipamento de SAPNC; b) Chapa de apoio com depósito cerâmico.

\section{Resultados e Discussão}

A montagem experimental para a SAPNC é apresentada na Figura 3. O equipamento de SAPNC é constituído de um cabeçote onde a ferramenta é acoplada, um sistema de telemetria, mesa suporte para posicionar as chapas, garras de fixação da peça, um sistema de circulação de fluido para o resfriamento da ferramenta e da mesa suporte e um dispositivo para fluxo de gás inerte para a proteção da ferramenta.

Detalhes do pino e ombro da ferramenta estão destacados no canto superior direito da Figura 3a; a figura mostra ainda a execução da soldagem para o AID UNS S32101, conforme será descrita adiante. Um exemplo da chapa de apoio com depósito cerâmico, que será acoplada à mesa de soldagem, é apresentado na Figura $3 b$.

O depósito de pós cerâmicos a base de óxido de alumínio (alumina) foi o primeiro testado. Este depósito apresenta excelentes propriedades refratárias e de resistência à erosão em altas temperaturas, tipicamente 840 a $1650{ }^{\circ} \mathrm{C}$. Combinações de

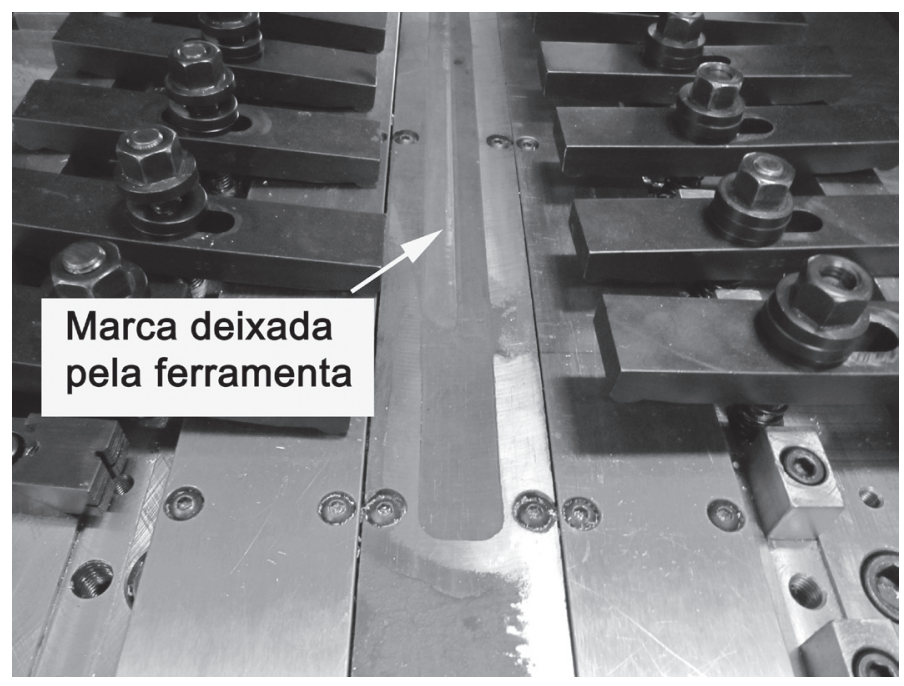

Figura 4. Mesa suporte contendo a chapa de apoio com depósito cerâmico após a realização da soldagem com acentuado desgaste. pós cerâmicos foram realizadas a fim de melhorar a resistência à abrasão/atrito até temperaturas $1100{ }^{\circ} \mathrm{C}$, visando a obtenção de um depósito cerâmico que combinasse resistência à abrasão, resistência à cargas elevadas e alta temperatura. Ambos os recobrimentos obtidos a partir de pós apresentaram excesso de porosidade, todavia é importante destacar que depósitos aspergidos termicamente apresentam uma faixa de porosidade em torno de $20 \%$ [15].

Cuidados especiais para a operação de retífica foram necessários, tais como baixa velocidade de avanço, proporcionando uma menor retirada de material e controle do aparecimento de trincas, uso em quantidade satisfatória de óleo de lubrificação, além de rebolo diamantado próprio para usinagem de materiais cerâmicos. A Figura 4 mostra a mesa, com a chapa de apoio com o depósito cerâmico, após a realização da soldagem de um AID, onde se observou a fragmentação do depósito e a presença de trincas.

Em uma segunda etapa, foram utilizados cordões cerâmicos de $\mathrm{Al}_{2} \mathrm{O}_{3}-12,3-\mathrm{TiO}_{2}$ [16] que permitiram produzir revestimentos com baixa porosidade (tipicamente 6-8 \%), alta densidade e baixa rugosidade. Revestimentos obtidos através deste processo permitem excelente desempenho durante os ciclos térmicos a altas temperaturas, além de permitirem atingir maiores espessuras do revestimento. Adicionalmente, foi possível a fabricação de uma mesa de apoio com depósito cerâmico de melhor desempenho e maior durabilidade após soldagem, que é particularmente crítico na soldagem de materiais com alta temperatura de fusão, os quais exigem altas cargas para a soldagem.

A seguir, são apresentados alguns sistemas soldados utilizando a mesa de apoio com depósito cerâmico de $\mathrm{Al}_{2} \mathrm{O}_{3}-12,3-\mathrm{TiO}_{2}$, bem como suas principais características indicando a viabilidade de uso deste e o impacto sobre a soldagem de alguns sistemas testados.

\subsection{Soldagem de aços baixa liga alta resistência}

A soldagem do sistema aço baixa liga alta resistência é um dos mais críticos para indústria de petróleo brasileira. Aços tubulares usados em transporte de óleo e gás natural a longas dis- 
tâncias, sobre uma alta pressão, essencialmente requerem alta resistência e tenacidade. A espessura e o diâmetro destes aços tendem a serem maiores com relação à eficiência de transporte e para diminuir o custo de transporte. Um acréscimo na resistência mecânica de aços tubulares é acompanhado do aumento da tenacidade à fratura. Para aços X75 uma microestrutura satisfatória para promover o endurecimento mecânico é a ferrita poligonal. Grades acima da X75 requerem uma microestrutura com matriz dura (ferrita acicular ou bainita) ou alta taxa de endurecimento (ferrita poligonal + constituinte martensita-austenita-MA). Outras metodologias utilizadas para obter aços de maior resistência mecânica são a manipulação da composição química ou uso de resfriamento acelerado após laminação controlada [17]. Entretanto, manter essa microestrutura durante os processos convencionais de soldagem não é trivial, já que processos convencionais por fusão geram a transformação da matriz ao promover o crescimento significativo dos grãos de ferrita e a transformação do constituinte MA [18]. O processo de SAPNC tem permitido alcançar microestruturas similares atingindo excelentes propriedades mecânicas e, para algumas condições, aumento da resistência mecânica como consequência do refinamento do tamanho de grão e formação de microestruturas tais como bainita granular e ferrita, como no caso do aço ISO 3183 X80M [19]. Manter ou melhorar o comportamento mecânico das juntas soldadas é o sucesso de processo SANPC; no entanto a obtenção de juntas consolidadas com penetração completa, bem como uma mesa suporte, que resista às altas cargas e temperaturas envolvidas no processo, é uma necessidade.

Neste trabalho, foram utilizadas chapas de $500 \mathrm{~mm} \times 90,0$ $\mathrm{mm} \times 12,0 \mathrm{~mm}$, do aço ISO $3183 \mathrm{X} 80 \mathrm{M}$ unidos pelo processo de SAPNC. A soldagem foi realizada na direção normal à direção de laminação objetivando futuros estudos em comparação a juntas circulares de soldagem a arco. Uma macrografia da junta soldada do aço é apresentada na Figura 5.

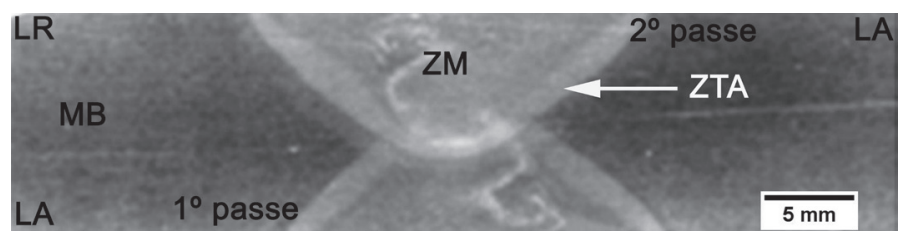

Figura 5. Macrografia da junta soldada em dois passes do aço ISO 3183 X80M mostrando a zona misturada (ZM), zona termicamente afetada (ZTA) e os lados de avanço (LA) e retrocesso (LR) da ferramenta de SAPNC.

Em especial, a penetração completa não é uma grande preocupação nesta configuração de soldagem, visto que é realizada em dois passes, todavia as cargas envolvidas são altas e a prevenção da deformação da mesa é muito importante. A Figura 6 apresenta a evolução dos parâmetros durante o processo de SAPNC para a união do aço ISO 3183 X80M. Observa-se que no início de soldagem a força axial aproxima-se de $40 \mathrm{kN}$; esta etapa se refere a inserção da ferramenta na chapa ainda fria. Esta é uma das etapas mais críticas durante a soldagem por atingir maiores cargas e pode causar a deformação da mesa da máquina. O uso da mesa de apoio com depósito cerâmico permitiu suportar estas cargas sem deformar plasticamente, inclusive para pa- râmetros mais severos [5]. Adicionalmente, o depósito cerâmico permitiu confinar o calor das altas temperaturas impostas na junta soldada, facilitando o aquecimento inicial e a estabilidade durante o percurso da ferramenta. O perfil térmico da ferramenta de SAPNC está mostrado na Figura 6a.

Para o aço ISO 3183 X80M, ambas as juntas soldadas (parâmetros 350 e $500 \mathrm{rpm}$ e $100 \mathrm{~mm} \cdot \mathrm{min}^{-1}$ ) apresentaram um aumento de resistência mecânica e rompimento no metal de base conforme mostra a Figura 6 b. A tensão limite de resistência à tração para o aço soldado com $500 \mathrm{rpm}$ foi $(646 \pm 8) \mathrm{MPa}$, ligeiramente inferior aos $686 \mathrm{MPa}$ do metal de base [19,20], todavia superior aos $621 \mathrm{MPa}$ requerido pela norma ISO 3183 [21]. Ensaios de dobramento segundo a mesma norma indicaram ausência de descontinuidades.

\subsection{Soldagem de aços inoxidáveis duplex}

O sistema aço inoxidável duplex (AID) apresenta uma combinação de resistência mecânica e à corrosão que permitem que estes aços sejam largamente utilizados nas indústrias petroquímica e de óleo e gás. Uma microestrutura formada por frações aproximadamente iguais de ferrita e austenita proporciona aos AIDs alta resistência ao trincamento por corrosão-sob-tensão, corrosão localizada e uma resistência mecânica superior a dos aços inoxidáveis austeníticos convencionais (AIA), combinada a uma boa tenacidade [22]. Embora, os AIAs continuem sendo objeto de continuados estudos devido a sua conformabilidade, uma das mais demandadas propriedades deste tipo de aço em aplicações industriais [23,24].

Comumente, a combinação de aproximadamente $50 \%$ de ferrita e $50 \%$ de austenita é necessária para atingir a melhor combinação de propriedades mecânicas e de resistência à corrosão dos AIDs [22]. Todavia, durante um ciclo térmico, os AIDs podem apresentar fragilização de baixa e de alta temperatura devido à precipitação de fases intermetálicas e ao crescimento de grão por sobreaquecimento durante a soldagem. A fragilização de baixa temperatura ocorre na faixa de temperaturas de 300 a $500{ }^{\circ} \mathrm{C}$, enquanto a fragilização de alta temperatura acontece entre 600 a $1000{ }^{\circ} \mathrm{C}$, com precipitação de inúmeras fases deletérias, entre elas, a fase sigma. Esta fase compromete a tenacidade à fratura e a resistência à corrosão destes aços. A faixa de precipitação da fase sigma depende da composição química da liga e, geralmente, encontra-se na faixa de temperaturas de 600 a 950 ${ }^{\circ} \mathrm{C}$; ela surge da decomposição eutetóide da ferrita metaestável.

A fase $\sigma$ ocorre preferencialmente em sítios ferríticos, onde a concentração de cromo e molibdênio é alta; durante a formação $\sigma$, a vizinhança fica empobrecida de $\mathrm{Cr}$ e Mo e pode se transformar em austenita secundária [25]. A tecnologia SAPNC apresenta algumas vantagens para a soldagem dos AIDs. Dentre elas, pode-se ressaltar a união no estado sólido excluindo os problemas decorrentes da solidificação. Adicionalmente, a microestrutura favorável tem sido mantida durante o processo de SAPNC e a precipitação de fases deletérias não tem sido observada [26-28]. Poucos trabalhos têm estudado processo de soldagem por atrito de aços inoxidáveis duplex com especial atenção à penetração completa. No estudo realizado por Steel et al. [29] a penetração total não foi alcançada e os autores concentraram-se no estudo da metalurgia inerente ao processo. Outros traba- 

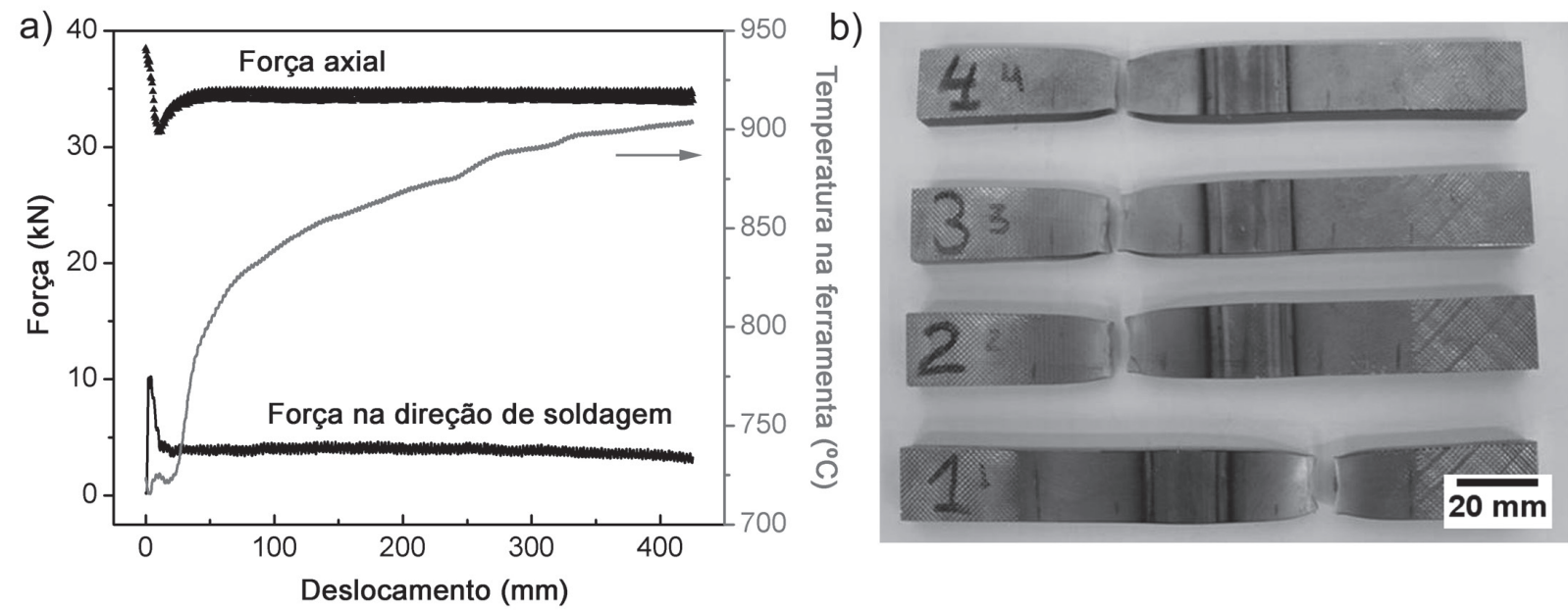

Figura 6. SAPNC do aço ISO 3183 X80M (API 5L X80). a) Evolução das forças axial e transversal (na direção de soldagem) e temperatura medida na ferramenta. Parâmetros de soldagem $350 \mathrm{rpm}$ e $100 \mathrm{~mm} \cdot \mathrm{min}^{-1}$. b) Ensaio de tração segundo a norma ISO 3183-07 realizados em amostras transversais soldadas usando $500 \mathrm{rpm}$.
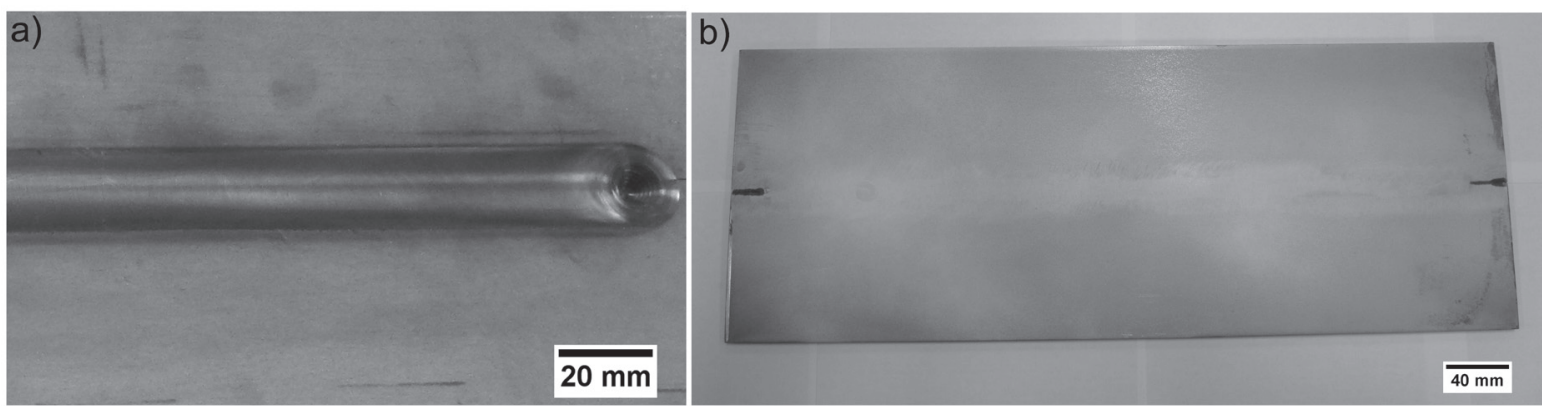

Figura 7. Junta soldada do aço inoxidável duplex UNS S32101: a) face e b) raiz após líquido penetrante.

lhos [26,27] não indicaram se a penetração total foi alcançada. A falta de penetração completa deixa uma superfície livre próxima à raiz que faz o papel de um entalhe no material favorecendo o rompimento do mesmo naquela região. Santos et al. [28,30] estudando a soldagem por atrito com pino para o AID S32205 obteve penetração completa para chapas de espessura de $6 \mathrm{~mm}$ usando a chapa de apoio com depósito cerâmico.

A Figura 7 apresenta a face e a raiz da junta soldada. $\mathrm{Na}$ Figura 7a observa-se um bom acabamento superficial dispensando procedimentos de limpeza pós-soldagem, destacando-se a ausência de rebarba, o que indica que a penetração era adequada e a fluidez do metal não foi excessiva. $\mathrm{Na}$ junta, após ensaio de líquido penetrante, indicada na Figura $7 b$, não foi observada falta de penetração, nem deformação ou abertura da chapa por excesso de penetração.

A macrografia da seção transversal indica a região da junta soldada é apresentada na Figura 8a. Nota-se que a região soldada alcança a raiz. É interessante destacar que para os parâmetros adotados de soldagem, a mesa de apoio com depósito cerâmico permaneceu intacta após processo. Na Figura $8 \mathrm{~b}$ e Figura $8 \mathrm{c}$ são mostradas as vistas frontal e lateral da junta soldada após ensaio de dobramento; observa-se que não houve abertura de raiz corroborando a penetração completa para o aço inoxidável duplex UNS S32101. Resultados semelhantes foram encontrados para o aço inoxidável duplex UNS S32205 [28,30] e os superduplex UNS S32750 e S32760 [31].

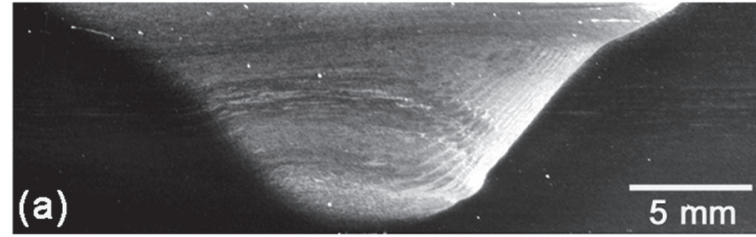

(b)

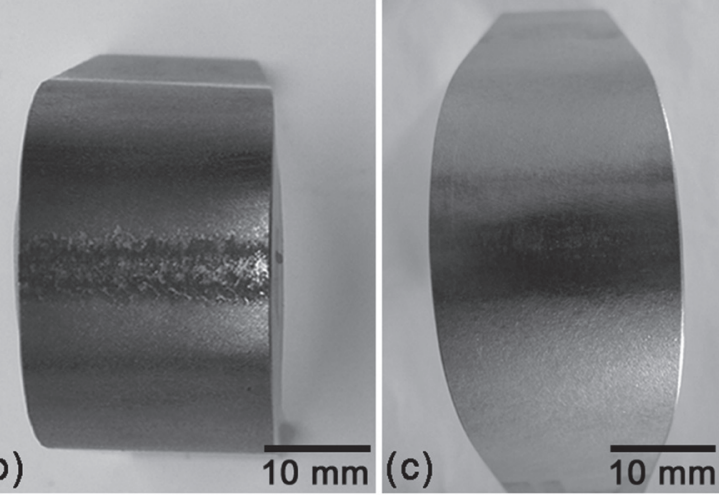

Figura 8. a) Macroestrutura mostrando a seção transversal da junta soldada do aço UNS S32101. Vista de topo da raiz das juntas soldadas dos aços (b) UNS S322101 e (c) UNS S32205 submetidos a ensaio de dobramento.

Ensaios de tração em amostras retangulares transversais mostraram um aumento da resistência mecânica da junta. Conforme se verifica na Figura 9 para o AID UNS S32101, o rompimento 
das amostras ocorreu no metal de base. Esse comportamento também foi observado para os aços AISD UNS S32750 e S32760.

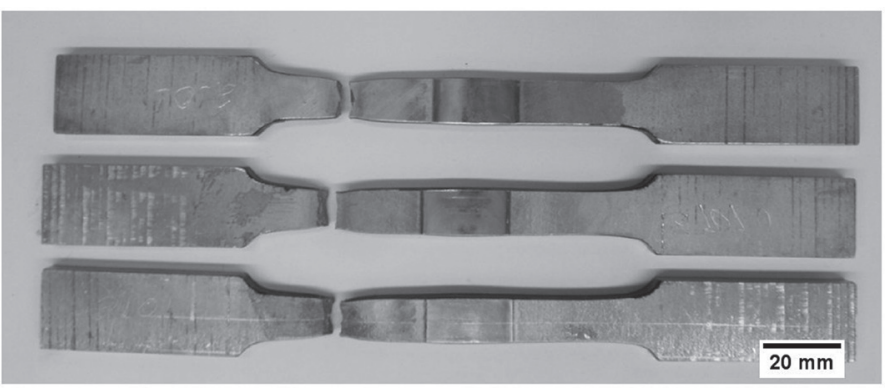

Figura 9. Ensaio de tração em amostras transversais do aço AID UNS S32101.

O resumo das propriedades mecânicas para o metal de base e para a junta soldada está apresentado na Tabela 2. Testes preliminares indicaram a abertura de raiz em função da obtenção de penetração incompleta. $\mathrm{O}$ uso da mesa de apoio com depósito cerâmico permitiu atingir juntas consolidadas com penetração completa e a obtenção de juntas de alto desempenho.

Tabela 2. Propriedades mecânicas do metal de base e da junta soldada. (1) Certificado de inspeção Outokumpu [32] e (2) Certificado de inspeção Weir Materials [33].

\begin{tabular}{|c|c|c|c|c|}
\hline UNS & Região/tipo & LE (MPa) & LR (MPa) & Al (\%) \\
\hline \multirow{2}{*}{32101} & Metal de base & $530^{(1)}$ & $700^{(1)}$ & $30^{(1)}$ \\
\cline { 2 - 5 } & Junta soldada & $610 \pm 15$ & $754 \pm 23$ & $24 \pm 1$ \\
\hline \multirow{2}{*32750}{} & Metal de base & $550^{(1)}$ & $795^{(1)}$ & $20^{(1)}$ \\
\cline { 2 - 5 } & Junta soldada & $725 \pm 24$ & $897 \pm 23$ & $21.8 \pm 0.3$ \\
\hline \multirow{2}{*}{32760} & Metal de base & $619^{(2)}$ & $871^{(2)}$ & $25^{(2)}$ \\
\cline { 2 - 5 } & Junta soldada & $632 \pm 19$ & $830 \pm 23$ & $23 \pm 1$ \\
\hline
\end{tabular}

Nota: LE: tensão limite de escoamento, LR: tensão limite de resistência à tração, $\mathrm{Al}(\%)$ : alongamento percentual. * intervalo de confiança $95 \%$. Número de amostras (n) $=3$ os ensaios de tração em amostras retangulares transversais.

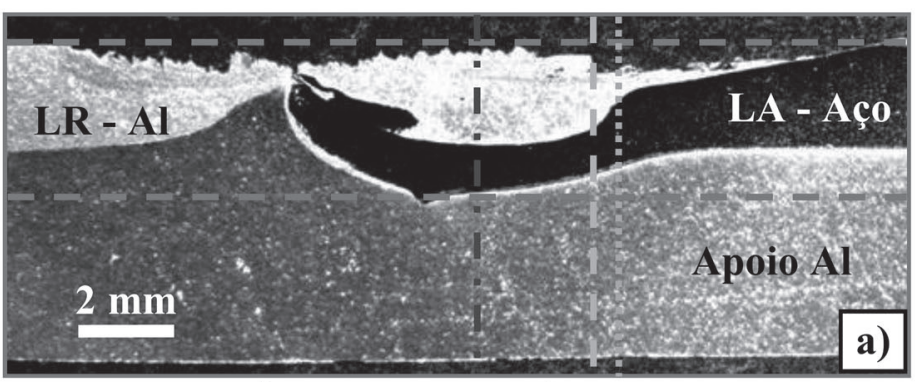

\subsection{Soldagem dissimilar aço-alumínio}

O uso do sistema alumínio-aço é um desejo de vários seguimentos da indústria automobilística, aeronáutica e aeroespacial visando a redução do peso dos veículos sem comprometer a integridade estrutural dos mesmos. A junção alumínio-aço é predominantemente realizada através de uniões mecânicas como rebites e parafusos, e sua junção por meio dos processos tradicionais de soldagem resulta na formação de compostos intermetálicos (CIM) [34]. Processos como a soldagem a laser, difusão, ultrassom e laminação já foram empregados com resultados promissores, entretanto persiste a formação dos CIM [35]. Desta forma, existe hoje uma demanda importante pelo desenvolvimento de tecnologias que permitam a união eficiente destas duas famílias de materiais.

A SAPNC tornou-se uma alternativa importante uma vez que a soldagem se realiza em estado sólido, o que diminui significativamente a formação de fases deletérias como os citados CIM [36,37]. Porém, durante a SAPNC do sistema alumínio-aço foi observada que a associação de uma junta soldada com bom acabamento superficial e penetração completa é extremante complexo. Adicionalmente, o aumento do aporte energético visando atingir a penetração completa trazia como prejuízo a aderência do alumínio à ferramenta de SAPNC e à mesa suporte [38].

A Figura 10 apresenta o efeito da penetração e o deslocamento da ferramenta na penetração do metal; nas imagens fica claro como o alumínio plastificado é agitado pela ferramenta, enquanto o aço é obrigado a escoar por baixo da ferramenta, deformando a chapa de apoio, que neste caso é a liga de alumínio AA5052. Uma das consequências é a aderência da junta soldada no backing; o mesmo efeito, de deformação e aderência, se observa ao usar chapas de apoio endurecidas por tratamento térmico, como o aço AISI SAE 1045 temperado. A deformação e aderência na chapa de apoio podem ser reduzidas diminuindo a penetração da ferramenta e/o deslocamento (offset), porém, sob essas condições, não é possível alcançar a penetração total e a união entre os materiais.

O uso de chapa de apoio com depósito cerâmico, além de permitir manter confinado o material plastificado possibilitou o uso de deslocamentos da ferramenta suficientes para corrigir

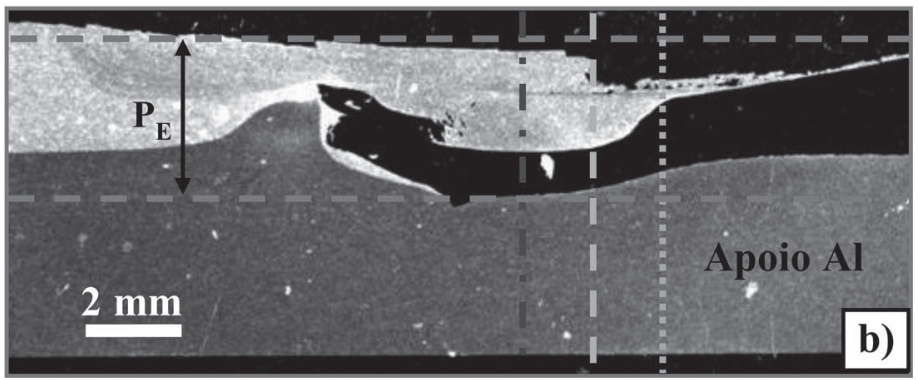

\begin{tabular}{|c|c|c|}
\cline { 2 - 3 } \multicolumn{1}{c|}{} & a) & b) \\
\hline $\mathbf{D}_{\mathrm{T}}[\mathbf{m m}]$ & $+0,5$ & $+1,5$ \\
\hline $\mathbf{P}_{\mathrm{E}}[\mathbf{m m}]$ & 2,6 & 2,8 \\
\hline
\end{tabular}

$\mathrm{P}_{\mathrm{E}}$ : Profundidade efetiva alcançada pelo material de soldagem.

$\mathrm{D}_{\mathrm{T}}$ : Deslocamento da tangente do pino da ferramenta.

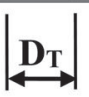

Figura 10. Junta alumínio-aço soldada mediante SAPNC, empregando penetração da ferramenta de $1,8 \mathrm{~mm}, \mathrm{D}_{\mathrm{T}}+0,5 \mathrm{e}+1,5 \mathrm{~mm}$, e chapa de apoio de alumínio. A linha de centro corresponde ao eixo da ferramenta, a tracejada à linha original da junta e a pontilhada ao deslocamento da tangente do pino. Na figura $\mathrm{P}_{\mathrm{E}}$ corresponde a penetração efetiva alcançada pela soldagem, enquanto $\mathrm{D}_{\mathrm{T}}$ indica $\mathrm{o}$ deslocamento da ferramenta (offset) em termos do deslocamento da tangente do pino da mesma. 
a formação de falta de preenchimento, mantendo uma aparência da superfície adequada [39]. Para destacar a importância do apoio na obtenção de juntas soldadas sem defeitos, a Figura 11 apresenta duas juntas dissimilares soldadas como os parâmetros apresentados na Tabela 1, mas com deslocamentos diferentes.

Em ambos os casos, o acabamento superficial é supreendentemente bom (Figura 11a), comparado com os resultados iniciais e outros trabalhos $[40,42]$. Para o deslocamento de $0,5 \mathrm{~mm}$ se observa um defeito de raiz ao longo da linha da junta (Figura $11 \mathrm{~b}$ ), evidente no teste de dobramento (Figura 11c). Por outro lado, o aumento de $1,5 \mathrm{~mm}$ do deslocamento da ferramenta evita a formação deste grave defeito, sem prejudicar o aspecto da superfície.

Na Figura 12 é apresentada a macrografía de ambas as juntas, das quais se destaca a ausência de vazios no interior da zona misturada (ZM). A Figura 12a indica, por meio de um círculo, o local de abertura da junta no teste de dobramento. Esse ponto corresponde à linha original da junta, a qual não foi suficientemente deformada para obter a junção dos metais. A diferença do caso anterior, com o aumento do deslocamento da ferramenta, mais aço é compelido a se deformar, passando por baixo da ferramenta, a qual induz uma deformação severa de ambos os metais, aço e alumínio, permitindo atingir a consolidação da junta (Figura 12b). Se a chapa de apoio não tiver resistência suficiente, o aço empurrado para baixo pela ferramenta deformaria a chapa, gerando a adesão da junta à chapa (Figura 10).

Espera-se que o comportamento apresentado nas juntas alumínio-aço seja similar em juntas dissimilares de metais com diferenças significativas de resistência mecânica como alumínioaço, alumínio-cobre, cobre-níquel, dentre outras. Para juntas dissimilares entre materiais com resistência mecânica análoga, o deslocamento da ferramenta talvez não seja necessário, a menos

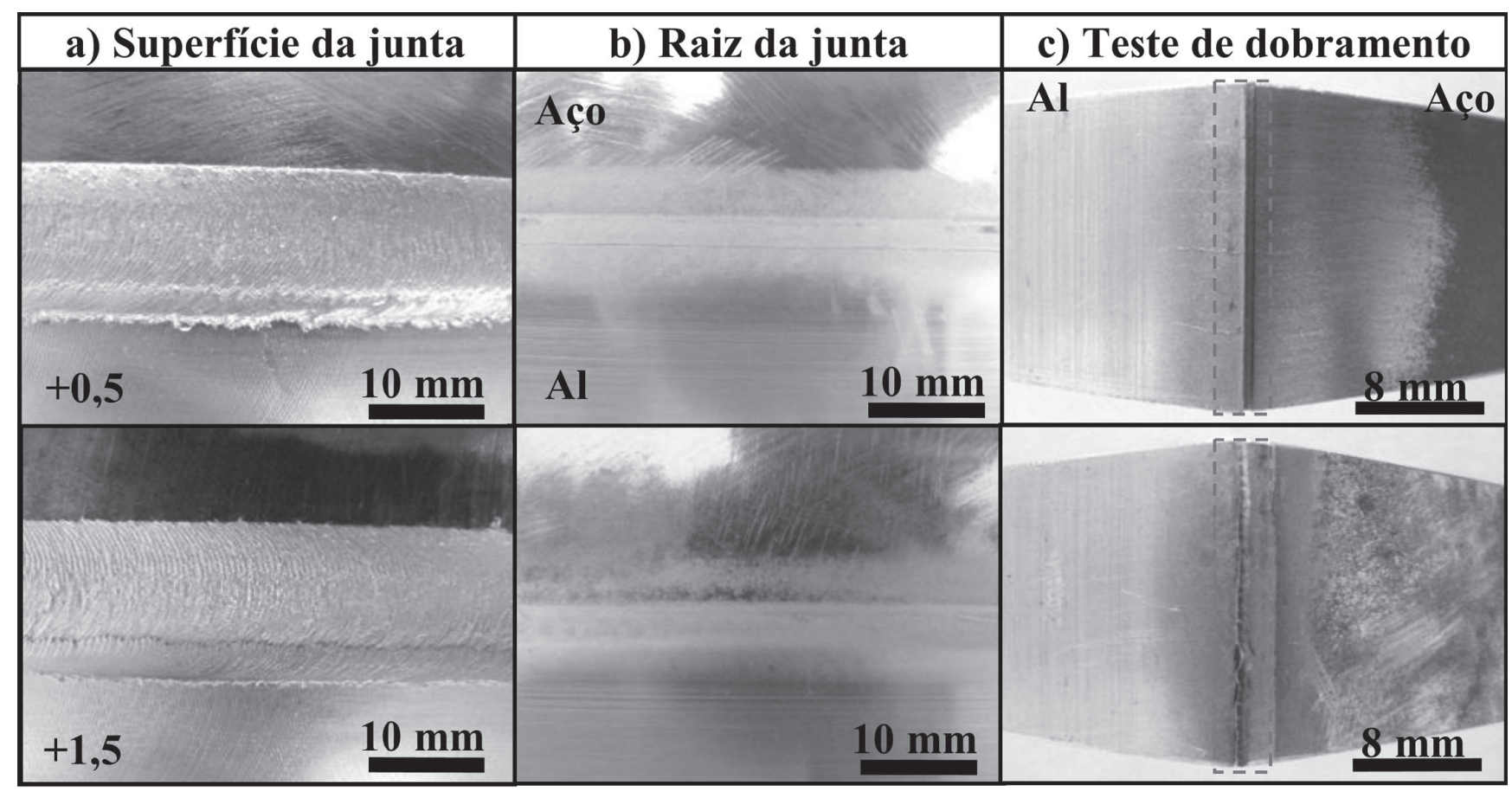

Figura 11. a) Aspecto da superfície, b) da raiz e c) testes de dobramento, das juntas alumínio-aço soldadas por SAPNC com offset de $+0,5 \mathrm{e}+1,5 \mathrm{~mm}$.

a)
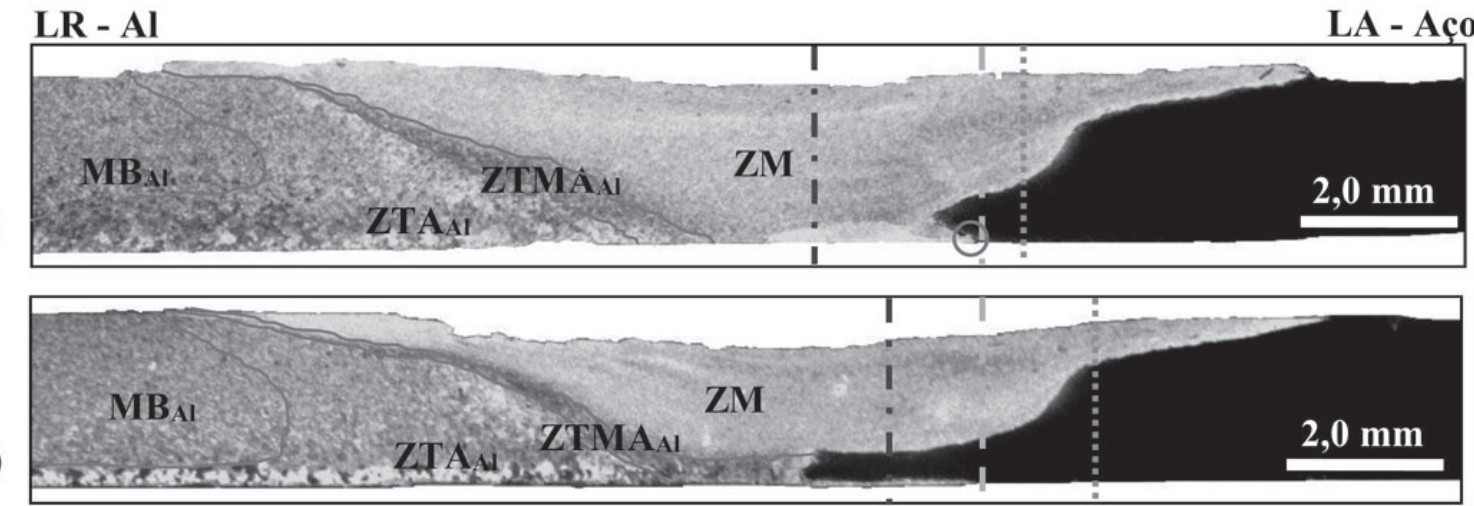

Figura 12. Macrografias das juntas soldadas com deslocamento de a) $+0,5$ e b) $+1,5 \mathrm{~mm}$. A linha de centro corresponde ao eixo da ferramenta, a linha tracejada à linha original da junta e a linha pontilhada ao deslocamento da tangente do pino da ferramenta. $\mathrm{O}$ círculo indica o local da abertura da raiz. 
que o objetivo seja modificar o grão de mistura entre os metais. Portanto, o comportamento será mais parecido com a união de juntas similares, como alumínio-alumínio, aço-aço, cobre-cobre, níquel-níquel, porém sendo necessário o uso de chapa de apoio com depósito cerâmico, pelas razões descritas anteriormente.

\section{Conclusões}

O depósito de materiais duro, seja de metal ou liga refratária ou cerâmica, na mesa suporte para SAPNC, permite alcançar alguns benefícios para soldagem do sistema, o principal é o de evitar a deformação da mesa suporte durante a soldagem ou processamento, prevenindo dano à máquina de SAPNC. Destaca-se a soldagem dos aços baixa liga e alta resistência que alcançaram altas cargas durante a penetração da ferramenta na junta fria.

Para os aços duplex, o depósito cerâmico permitiu a obtenção de juntas consolidadas com penetração completa, as quais exibiram uma melhoria em seu desempenho mecânico. Outras características que podem se destacadas são: para o caso de backing cerâmico, evita a fuga de calor, diminuindo a taxa de resfriamento e a formação da fase martensítica no caso de aços carbono; perda da têmpera devido ao ciclo térmico da mesa suporte construída em aço temperado, o que torna a mesa mais susceptível à deformação em presença de altas cargas. Em sistemas dissimilares, onde um dos materiais apresenta alta maleabilidade, o depósito de metal ou liga refratária ou material cerâmico evita a adesão do material amolecido à mesa.

$\mathrm{Na}$ soldagem de juntas alumínio-aço, o depósito cerâmico age como uma matriz de extrusão, ao conter o metal mais duro quando é forçado a passar pela parte inferior do pino, o que garante a formação de uma junta soldada com penetração total. A ausência do depósito cerâmico levaria ao uso de uma penetração e/ou deslocamento da ferramenta maior, na tentativa de conduzir o metal para o fundo da junta, trazendo como consequências o sobreaquecimento do metal, a aderência do alumínio à ferramenta, a deformação e aderência da junta na mesa, a formação excessiva de rebarba e a redução da vida útil de ferramenta.

\section{Agradecimentos}

Os autores agradecem à Petrobras e Finep por suporte financeiro; à Outokumpu, Aperam, Tenaris Confab pela doação dos materiais; ao CNPq e Fapesp por concessão de bolsas e à Ogramac pela realização da deposição dos pós e cordões cerâmicos.

\section{Referências Bibliográficas}

[1] THOMAS, M.; NICHOLAS, E.D.; NEEDHAM, J.C.; MURCH, M.G.; TEMPLESMITH, P.; DAWES, C.J. International Patent Application N. PCT/GB92/02203 and GB Patent Application No 9125978.8 and US Patent Application No. 5,460,317, 1991.

[2] SU, J.Q.; NELSON, T.W.; MISHRA, R.; MAHONEY, M. Microstructural investigation of friction stir welded 7050-T651 aluminium. Acta Materialia, v. 51, n. 3, p. 713-729, 2003.

[3] MISHRA, R.S.; MAHONEY, M.W. Friction stir welding and processing. Ohio: ASM International, 2007, 360p.

[4] MAEDA, M.: LIU, H.; FUJII, H.; SHIBAYANAGI, T. Temperature Field in the Vicinity of FSW-Tool During Friction Stir Welding of Aluminium Alloys. Welding in the World, v. 49, n. 3-4, p. 69-75, 2005

[5] HAMILTON, C.; DYMEK, S.; SOMMERS, A. A thermal model of friction stir welding in aluminum alloys. International journal of machine tools and manufacture, v. 48, n. 10, p. 11201130, 2008.

[6] ROSALES, M.J.C.; ALCANTARA, N.G.; SANTOS, J.; ZETTLER, R. The backing bar role in heat transfer on aluminium alloys friction stir welding. Materials Science Forum, v. 636, p. 459-464, 2010.

[7] UPADHYAY, P.; REYNOLDS, A.P. Effects of forge axis force and backing plate thermal diffusivity on FSW of AA6056. Materials Science and Engineering: A., v. 558, p. 394-402, 2012. [8] ACERRA, F., BUFFA, G.; FRATINI, L.; TROIANO, G. On the FSW of AA2024-T4 and AA7075-T6 T-joints: an industrial case study. The International Journal of Advanced Manufacturing Technology, v. 48, n. 9-12, p. 1149-1157, 2010.

[9] CUIA, L.; FUJIIA, H.; TSUJIB, N.; NOGIA, K. Friction stir welding of a high carbon steel. Scripta Materialia, v. 56, n. 7, p. 637-640, 2007

[10] SAEIDA, T.; ABDOLLAH-ZADEHB, A.; SAZGARIB, B. Journal of Alloys and Compounds, v. 490, n. 1-2, p. 652-655, 2010.

[11] XUE, P.; NI, D.R.; WANG, D.; XIAO, B.L.; MA, Z.Y. Effect of friction stir welding parameters on the microstructure and mechanical properties of the dissimilar Al-Cu joints. Materials Science and Engineering: A, v. 528, n. 13, p. 4683-4689, 2011. [12] NELSON, T.W.; SORENSEN, C.D.; PACKER, S.M. Anvil for friction stir welding high temperature materials. International Patent Application n. US 6,732,901 B2, 2004.

[13] ARBEGAST, W.J. A flow-partitioned deformation zone model for defect formation during friction stir welding. Scripta materialia, v. 58, n. 5, p.372-376, 2008.

[14] STEEL, R.J.; PETTERSSON, C-O; PACKER, S.M.; SORENSER, C.D.; SATO, Y.S.; NELSON, T.W; STERLING, C.J. Friction Stir Welding of SAF 2507 (UNS S32750) Super Duplex Stainless Steel. Stainless Steel World, v. 16, p. 27-31, 2004.

[15] LIMA, C.C.; TREVISAN, R. Aspersão Térmica: fundamentos e aplicações, $2^{\mathrm{a}}$ edição. São Paulo: Artliber Editora Ltda, 2007, 152p.

[16] SULZER METCO. Inspection certificate

[17] SHIN, S.Y., HWANG, B., KIM, S., LEE, S. Fracture toughness analysis in transition temperature region of API X70 pipeline steels, Mat. Sci. Eng. A, v. 429, p. 196-204, 2006.

[18] PONTREMOLI , M., BUFALINI , P., APRILE, A., JANNONE, C. Development of grade API X80 pipeline steel plates produced by controlled rolling, Metals Tech., v.11, p.504-514, 1984.

[19] SANTOS, T.F.A.; HERMENEGILDO, T.F.C.; AFONSO, C.R.M.; MARINHO, R.R.; PAES, M.T.P. Fracture toughness of ISO 3183 X80M (API 5L X80) steel friction stir welds. Engineering Fracture Mechanics, v. 77, p. 2937-2945, 2010.

[20] Usiminas. Inspection certificate no. 1247149, 2008.

[21] ISO 3183. Petroleum and Natural Gas Industries - Steel 
Pipe for Pipelines - Technical delivery conditions, $2^{\mathrm{a}}$ edition, 2007.

[22] LIPPOLD, J.C.; KOTECHI, D.J. Welding Metallurgy and Weldability of Stainless Steels. Ohio: John Wiley \& Sons Inc., 2005, 356p.

[23] SANTOS, T.F.A., ANDRADE, M.S. Internal Friction on AISI 304 Stainless Steels with Low Tensile Deformations at Temperatures between -50 and $20^{\circ} \mathrm{C} \mathrm{Adv}$. Mat. Sci. Eng. 2010: $1-8,2010$.

[24] SANTOS, T.F.A., ANDRADE, M.S. Avaliação dilatométrica da reversão das martensitas induzidas por deformação em um aço inoxidável austenítico do tipo ABNT 304, Matéria, v. 13, n. 4, p. 587-596, 2008.

[25] RAMIREZ, A.J.; LIPPOLD, J.C.; BRANDI, S.D. The Relationship between Chromium Nitride and Secondary Austenite Precipitation in Duplex Stainless Steels. Metallurgical and Materials Transactions A, v. 34, p. 1575-1597, 2003.

[26] SATO, Y.S.; NELSON, T.W.; STERLING, C.J.; STEEL, R.J.; PETTERSON, C.-O. Microstructure and mechanical properties of friction stir welded SAF 2507 super duplex stainless steel. Materials Science and Engineering A, v. 397, p. 376-384, 2005.

[27] SAEID, T.; ABDOLLAH-ZADEH, A.; ASSADI, H.; MALEK GHAINI, F. Effect of friction stir welding speed on the microstructure and mechanical properties of a duplex stainless steel. Materials Science and Engineering A, v. 496, p. 262-268, 2008.

[28] SANTOS, T.F.A., MARINHO, R.R.; PAES, M.T.P.; RAMIREZ, A.J. Microstructure evaluation of UNS S32205 duplex stainless steel friction stir welds. Revista Escola de Minas, v. 66, p. 187-191, 2013.

[29] STEEL, R.J.; PETTERSSON, C-O; PACKER, S.M.; SORENSER, C.D.; SATO, Y.S.; NELSON, T.W; STERLING, C.J. Friction Stir Welding of SAF 2507 (UNS S32750) Super Duplex Stainless Steel. Stainless Steel World, v. 16, p. 27-31, 2004.

[30] SANTOS, T.F.A.; IDAGAWA, H. S.; RAMIREZ, A.J. Thermal history in UNS S32205 duplex stainless steel friction stir welds. Science and Technology of Welding and Joining, v. 19, p. 150-156, 2013.

[31] SANTOS, T.F.A.; RAMIREZ, A.J. Correlating Microstructure and Performance of UNS S32750 and S32760 Superduplex Stainless Steels Friction Stir Welds. In: Proceedings of the twenty-first International Offshore and Polar Engineering Conference, Maui, 2011, p. 534-540.

[32] OUTOKUMPU. Inspection certificate $n^{\circ}$ 1781436-EN (UNS S32101), Inspection certificate $\mathrm{n}^{\circ}$ 1781438-EN (UNS S32750), 2009.

[33] WEIR MATERIALS. UNS S32760. Inspection certificate $\mathrm{n}^{\circ}$ 15688/0B, 2003.

[34] WATANABE, T.; TAKAYAMA, H.; YANAGISAWA, A. Joining of aluminum alloy to steel by friction stir welding, Journal of Materials Processing Technology, v. 178, p. 342-349, 2006 [35] AGUDO, L.; EYIDI, D.; SCHMARANZER, C.H.; ARENHOLZ, E.; JANK, N.; BRUCKNER, J.; PYZALLA, A.R.. Intermetallic $\mathrm{Fe}_{\mathrm{x}} \mathrm{Al}_{\mathrm{y}}$-phases in a steel/Al alloy fusion weld, Journal of Materials Science and Engineering, v. 42, p. 4205-4214, 2007.

[36] UZUN, H.; DALLE DONNE, C.; ARGAGNOTTO, A.;
GHIDINI, T.; GAMBARO, C. Friction Stir Welding of Dissimilar Al 6013-T4 to X5CrNi18-10 Stainless Steel, Materials and Design, v. 26, p. 41-46, 2005

[37] CHEN T.P.; LIN, W.-B. Optimal FSW process parameters for interface and welded zone toughness of dissimilar aluminum-steel joint, Science and Technology of Welding and Joining v. 15 , n. 4 , p. 279-285, 2010.

[38] TORRES, E.A.; RAMIREZ, A.J. União de juntas dissimilares alumínio-aço de chapas finas pelo processo de soldagem por atrito com pino não consumível (SAPNC). Soldagem \& Inspeção, v. 16, n. 3, p. 265-273, 2011.

[39] TORRES, E.A.; RAMIREZ, A. J. Efeito dos parâmetros de processo na obtenção e na microestrutura de juntas alumínio-aço realizadas mediante soldagem por atrito com pino não consumível (SAPNC), Soldagem \& Inspeção, v. 18, n. 3, p. 245-256, 2013.

[40] CHEN, C.M.; KOVACEVIC., R. Joining of Al 6061 alloy to AISI 1018 steel by combined effects of fusion and solid state welding, International Journal of Machine Tools and Manufacture, v. 44, p. 1205-1214, 2004.

[41] COELHO, R.S.; dos SANTOS, J.; KOSTKA, A. EBSD Technique Visualization of Material Flow in Aluminum to Steel Friction-Stir Dissimilar Welding, Advanced Engineering Materials, v. 10, n. 12, p. 1127-1133, 2008.

[42] CHEN, T. Process parameters study on FSW joint of dissimilar metals for aluminium-steel, Journal of Materials Science, v. 44, p. 2573-2580, 2009. 